OPEN ACCESS

Edited by:

Pablo Brañas-Garza,

Middlesex University, United Kingdom

Reviewed by:

Marcello Sartarelli,

University of Alicante, Spain

Valerio Capraro,

Centrum Wiskunde \& Informatica,

Netherlands

*Correspondence:

Lionel Page

lionel.page@qut.edu.au

Received: 31 August 2017 Accepted: 28 November 2017 Published: 15 December 2017

Citation:

Xie Z, Page L and Hardy B (2017) Investigating Gender Differences under Time Pressure in Financial Risk

Front. Behav. Neurosci. 11:246. doi: 10.3389/fnbeh.2017.00246

\section{Investigating Gender Differences under Time Pressure in Financial Risk Taking}

\author{
Zhixin Xie ${ }^{1}$, Lionel Page ${ }^{1 *}$ and Ben Hardy ${ }^{2}$ \\ ${ }^{1}$ Queensland Behavioral Economics Group, School of Economics and Finance, Queensland University of Technology, \\ Brisbane, QLD, Australia, ${ }^{2}$ School of Finance and Management, SOAS University of London, London, United Kingdom
}

There is a significant gender imbalance on financial trading floors. This motivated us to investigate gender differences in financial risk taking under pressure. We used a well-established approach from behavior economics to analyze a series of risky monetary choices by male and female participants with and without time pressure. We also used second to fourth digit ratio (2D:4D) and face width-to-height ratio (fWHR) as correlates of pre-natal exposure to testosterone. We constructed a structural model and estimated the participants' risk attitudes and probability perceptions via maximum likelihood estimation under both expected utility (EU) and rank-dependent utility (RDU) models. In line with existing research, we found that male participants are less risk averse and that the gender gap in risk attitudes increases under moderate time pressure. We found that female participants with lower 2D:4D ratios and higher fWHR are less risk averse in RDU estimates. Males with lower 2D:4D ratios were less risk averse in EU estimations, but more risk averse using RDU estimates. We also observe that men whose ratios indicate a greater prenatal exposure to testosterone exhibit a greater optimism and overestimation of small probabilities of success.

Keywords: testosterone, 2D:4D, fWHR, time pressure, risk taking

\section{INTRODUCTION}

Why are there so few women trading in the markets? The last 50 years have seen more and more women participating in the workforce. In many professions, the percentage of women approaches or exceeds 50\% (see for example, Chambers Partners, 2014; Kaiser Family Foundation, 2015; Catalyst, 2016). Yet some professions stay firmly outside of this evolution. Professional traders on financial trading floors are unambiguously one of these cases. Although women represent more than half the workforce in financial services (Sethi et al., 2013) they are typically in marketing, compliance or HR roles (Jäkel and Moynihan, 2016). What scant data there is suggests that women comprise 15\% of junior investment and trading roles (Green et al., 2009; Lietz, 2012).

The causes of this gender imbalance are still not well understood. While in some professions it is argued that an invisible ceiling prevents the access of women, (Korzec, 2000; Williams and Richardson, 2010; Truss, 2016) this is unlikely to be the case in finance, where performance pressure pushes firms to look for the best talent at all costs. A number of explanations have been advanced in both the academic and practitioner literature for the relative absence of women. Some explanations suggest that there are fundamental differences in cognition between the sexes (e.g., Sapienza et al., 2009), some that there are psychological differences (see Charness and Rustichini, 2011) and some 
that social factors account for differences in behavior (Byrnes et al., 1999; Saqib and Chan, 2015) and that this, in turn accounts for the differences in representation. This study investigates a potential factor driving gender imbalance on trading floors: differences between men's and women's risk preferences, particularly under time pressure.

Trading is a pressurized activity where stakes are high and time is short (Oberlechner and Nimgade, 2005; Kocher and Sutter, 2006). To examine the relationship between risk-taking, time pressure and gender, we use a standard risk elicitation experiment with substantial incentives, where biological markers of prenatal exposure to testosterone are measured for men and women and where choices are observed under different degrees of time pressure.

This paper contributes to three distinct bodies of research: the literature on gender differences in risk attitudes, the literature on gender differences in financial behavior and careers, and the literature on stability of preferences.

There is a substantial body of research on gender differences in risk attitudes. One of the most common and consistent findings in the risk preference literature has been that men take more risk than women (Powell and Ansic, 1997; Byrnes et al., 1999; Eckel and Grossman, 2002; Croson and Gneezy, 2009). Croson and Gneezy (2009) discussed some explanations of the gender difference in risk taking, which included emotions, overconfidence and risk as challenge or threats. The search for the roots of these gender differences has pointed to the role played by the androgen hormone testosterone. Testosterone (T) is an androgenic hormone which plays a pivotal role in sexual differentiation. This organizing role of testosterone is what alters the course of fetal development from the default female patternin effect, it is what makes men men. In addition to this organizing and differentiating role, testosterone, is also thought to modulate behavior in a number of ways. Testosterone levels have been positively associated with number of behaviors in adult men, including aggression (Archer, 2006), sensation seeking (Roberti, 2004), hostility (Hartgens and Kuipers, 2004), mate-seeking (Roney et al., 2003), and dominance (Mazur and Booth, 1998). Research in economics has shown that markers of pre-natal exposure to testosterone-in effect, measures of testosterone's organizing effects-have an impact on risk attitude (Coates and Page, 2009; Brañas-Garza and Rustichini, 2011; Garbarino et al., 2011; Brañas-Garza et al., 2017). We complement this research by investigating how prenatal testosterone exposure affects risk attitude decomposed into outcome sensitivity and probability sensitivity (in a RDU model).

This paper also contributes to the substantial literature on gender differences in financial behavior, which have been observed in both real and experimental markets. In the real market, men believe they are more competent than women (Graham et al., 2009), are more overconfident (Grinblatt and Keloharju, 2009), and trade more often than women (Barber and Odean, 2001). Deaves et al. (2010) found no gender effect in trading but observed that women traded less than men. Experimental studies, such as Fellner and Maciejovsky (2007), find that women submitted fewer offers and engaged in fewer trades than men. Eckel and Füllbrunn (2015) showed that all-male markets yield significant price bubbles while all-female markets produced prices that were below fundamental value. A variety of reasons have been suggested for these differences in observed behavior. Research has suggested that men are more competitive (Niederle and Vesterlund, 2007), so drive harder to beat others. Men are perceived as selfish (Aguiar et al., 2009; Brañas-Garza et al., 2016) and actually are more selfish (Rand, 2016).

One of the differences between men and women is in levels of testosterone. Coates et al. (2010) proposed a hypothesis suggesting that the irrational exuberance observed during market bubbles is mediated by testosterone. They speculated that men and women traders are likely to behave differently with male traders' behavior driving market instability. In the present study, we compare men and women's financial risk taking under time pressure. Time pressure is a key aspect of financial decisions on the trading floor. Traders make decisions in financial markets within seconds after new information becomes available (Busse and Green, 2002). In the light of this we theorized that gender differences under time pressure may be one of the factors driving the gender imbalance observed in these environments. If men and women make different decisions under time pressure then it may be that the market favors one decision making profile over another, and so favors one gender over another. Kocher et al. (2013) found that risk aversion for gains was robust under time pressure, whereas risk-seeking for losses turned into risk aversion under time pressure. For mixed prospects, i.e., a mixture of gains and losses, subjects became more loss-averse and more gain-seeking under time pressure. Nursimulu and Bossaerts (2014) found that the time-varying sensitivities translated into decreased risk aversion and increased probability distortions for gains under extreme time pressure. Capraro et al. (2017) examined the effect of time pressure and degree of deliberation on decisions about the allocation of resources. They did not, however, examine gender effects. Although there has been work on social preferences and time pressure, there is less work on risk attitudes under time pressure and very little on gender difference in risk attitudes under time pressure.

Finally, by investigating variations in risk preferences under time pressure, the paper contributes to the literature on the stability of economic preferences. The stability of preferences has been a shibboleth of much economic theory since Stigler and Becker's seminal paper (Stigler and Becker, 1977). Recent research, however, has shown that preferences are not as stable as hitherto supposed. Both explicit factors, for example time pressure (Kocher and Sutter, 2006), and implicit ones, such as levels of the hormone cortisol (Kandasamy et al., 2014), mean that people make different choices. Research in a number of fields has shown that time pressure affects the nature of interpersonal interaction, such as the levels of cooperation (Rand et al., 2012, 2014; Capraro and Cococcioni, 2015, 2016; Rand, 2016). Despite this, the impact of time pressure has been largely ignored by economics (Kocher and Sutter, 2006; De Paola and Gioia, 2016) and, what work there has been, has not clearly delineated the influence of time pressure on decision-making. Work rooted in experimental psychology has examined the speed vs. accuracy trade-off. Speedy decisions are thought to be of poorer quality, 
as time pressure prevents effective information processing. This, in turn, leads individuals to fall back on heuristics rather than the information presented (see Kocher and Sutter, 2006). Where risk appetite is evaluated, most research has suggested that risk-taking increases with time pressure (Huber and Kunz, 2007; Young et al., 2012; Kocher et al., 2013; Hu et al., 2015). Only Young et al. (2012) examined gender differences, but found none.

Our research finds that, in line with previous research, male participants took more risk. In addition, we identified three patterns which shed new light on gender differences in risk attitudes. First, the degree of testosterone that men are exposed to in utero correlates with riskier decisions in later life. Second, testosterone exposure was associated with more optimism and overweighting of small probabilities of chances under time pressure for male participants, relative to female participants.

\section{MOTIVATIONS AND HYPOTHESES}

There are two broad classes of explanation for why women are underrepresented in front office roles. The first is that women behave differently to men, and in ways which are not valued in financial services. The second group is that the front office provides an environment that neither welcomes women, nor is attractive to them. These two positions poles of the argument could be stylized as nature and nurture.

This paper focusses on the nature element of the debate. The differences between men and women begin at the moment of fertilization where the fusion of genetic material from each parent determines whether the fetus develops as a male or female. How do these biological differences play out so that, years later, men and women make, on average, very different decisions?

Biological sex is determined at conception and many of its effects are cemented in utero. The default pattern for developing embryos is female, but the Y chromosome contains the SRY gene which transforms the indifferent gonad into male testes. These testes then produce testicular hormones (e.g., testosterone) which confers the male primary and secondary sex characteristics. Between 12 and 18 weeks of gestation male fetal plasma testosterone levels reach nine times that of females causing the formation of male external genitalia and conformational alterations in the brain and spinal cord (Breedlove and Hampson, 2002). This testosterone peak also affects the length of the digits. Intra-uterine testosterone levels have been found negatively correlated with the ratio between the second and fourth digits (index and ring fingers, known as the 2D:4D ratio) (Lutchmaya et al., 2004). Higher concentrations of fetal testosterone produce lower 2D:4D ratios and men typically have lower 2D:4D ratios than women (Manning et al., 1998; McIntyre, 2006). Interestingly, no relationship between testosterone and 2D:4D ratio is observed (Hollier et al., 2015) when testosterone levels in umbilical blood are measured at birth. This may be a timing issue, as the in utero testosterone peak (see above) has passed and the post-partum peak (Swerdloff et al., 2002) has yet to occur.

During puberty, another androgen peak results in the development of male secondary sex characteristics and has further effects on cerebral architecture. Again, this pubertal peak affects bodily conformation, notably in the ratio between facial width and height, or fWHR (Verdonck et al., 1999; Weston et al., 2007), with males having larger ratios than females.

These markers of testosterone exposure can be readily measured and impact on risk-taking and decision-making. Coates et al. (2009) found that male traders with lower 2D:4D had higher profitability and Coates and Page (2009) found that this result was entirely driven by greater risk-taking. Garbarino et al. (2011) designed a financially motivated decision-making experiment and found that: men had lower 2D:4D ratios than women and the difference was significant; women made more risk-averse choices compared with men, and both men and women with smaller digit ratios made riskier financial choices with effect being identical for men and women. Barel (2017) found that only women exhibited more financial risk taking with lower 2D:4D but higher optimism levels. However, no significant correlation between the $2 \mathrm{D}: 4 \mathrm{D}$ and risk preferences were observed by Schipper (2014). Drichoutis and Nayga (2015) found no effect of digit ratio on either risk or time preferences. Studies using 2D:4D ratios are potentially confounded by a number of factors such as ethnic groups (Manning et al., 2007). Consequently, the relationship between $2 \mathrm{D}: 4 \mathrm{D}$ and risk-taking is not conclusive. Brañas-Garza et al. (2017) provide a detailed review of this research. Little is known about the associations with fWHR. The differential impact of testosterone exposure on risk preferences for both genders remains inconclusive.

The 2D:4D ratio has been shown, in men, to be negatively correlated with good visual and spatial performance (Manning and Taylor, 2001; Kempel et al., 2005), dominance and masculinity (Fink et al., 2007), sensation-seeking (Fink et al., 2006), and overconfidence (Dalton and Ghosal, 2014; Neyse et al., 2016). Overconfident investors and those investors most prone to sensation seeking were found trading more frequently (Grinblatt and Keloharju, 2009). Tester and Campbell (2007) found that the significant relationship between the 2D:4D ratio and sporting achievement was nearly identical in both men and women. However, several traits were only found in women, for instance, sensation-seeking, psychoticism, neuroticism (Austin et al., 2002), verbal fluency (Manning, 2002) social cognition (Williams et al., 2003), and cognitive reflection (Bosch-Domènech et al., 2014). The predictions of the face width-to-height ratio (fWHR) were mostly found in men. Carré and McCormick (2008) found that male undergraduate students had a larger fWHR, higher scores of trait dominance, and more reactive aggression than female students. However, the individual differences in fWHR predict reactive aggression in men but not in women. Valentine et al. (2014) supported the finding that fWHR is a physical marker of dominance and men with higher ratios are more attractive to women. Lefevre et al. (2014) suggested links between fWHR and self-reported aggression in both men and women, as well as dominance in men, but not in women.

This study examines the relation between gender and risktaking in situations with and without time pressure. We summarize our investigation in three questions:

Question 1: Does time pressure increase an appetite for risk? 
Question 2: Is higher testosterone exposure associated with higher risk-taking?

Question 3: Is there heterogeneity by gender?

\section{METHODS}

\section{Experimental Design}

The experiment was programmed in zTree (Fischbacher, 2007) and conducted at Queensland University of Technology (QUT). Participants were recruited via the Queensland Behavioral Economics Group (QuBE) website, powered by Online Recruitment System for Economics and Experiments (ORSEE) (Greiner, 2004). ${ }^{1} 154$ students (74 females and 80 males) in total participated in 9 experimental sessions in this study and each experimental session lasted around 30-40 min. Upon entry to a laboratory at $\mathrm{QuBE}$, participants were randomly assigned to a computer terminal. They were asked to complete the task individually and independently.

To measure the markers of participants' testosterone exposure, photographs of their faces were taken and right hands were scanned (see Figure 1). Then, the facial width was measured by the distance between the left and the right zygion (bizygomatic width) and the facial height was measured by the distance between the upper lip and brow (upper facial height Carré and McCormick, 2008, see photograph in Figure 1). The lengths of the second and fourth digits were measured from the basal crease (i.e., the crease closest to the base of the finger) to the central point of the fingertip (Garbarino et al., 2011; Neyse and Brañas-Garza, 2014).

Participants then engaged in a standard risk preference elicitation task using Random Lottery Pair design (Hey and Orme, 1994). This task consists of three phases and 30 decisions between pairs of lotteries per phase ( 90 decisions in total). Further, to investigate the role of time pressure, there are different time constraints imposed in each phase: no constraint, 8 and $4 \mathrm{~s}$ to make a decision in one lottery pair. These are the time constraints chosen by Kocher et al. (2013) in their study of risky decisions under time pressure. An $8 \mathrm{~s}$ constraint represents a moderate time pressure, while $4 \mathrm{~s}$ is a situation of extreme time pressure where participants have very little time to make a decision after discovering the different outcomes and their probability. We adopt a within-subject approach, which allows us to gain statistical power by controlling for unobservable characteristics. However, it also runs the risk of creating ordering effects. Therefore, to mitigate this risk, we randomized the order of the phases across experimental sessions.

Participants were presented with a pair of pie charts describing the probabilities of four fixed monetary prizes of $0,15,30$, and $\$ 45$ (Australian Dollars). ${ }^{2}$ An example of lottery pairs is shown

\footnotetext{
${ }^{1}$ The research ethics require participants being anonymous and unidentifiable during and after the experiment, therefore participants' personal information, such as age, faculty and ethnic groups were not collected. The ethics committee at QUT Business School approved this research and participants gave written informed consents before partaking the experiment.

${ }^{2}$ We used the set of lotteries from Conte et al. (2011) and Hey (2001) also used by many other studies including Moffatt (2005) and Conte et al. (2011). Hey (2001) explained the logic of the choice of lotteries. Each lottery can be associated
}

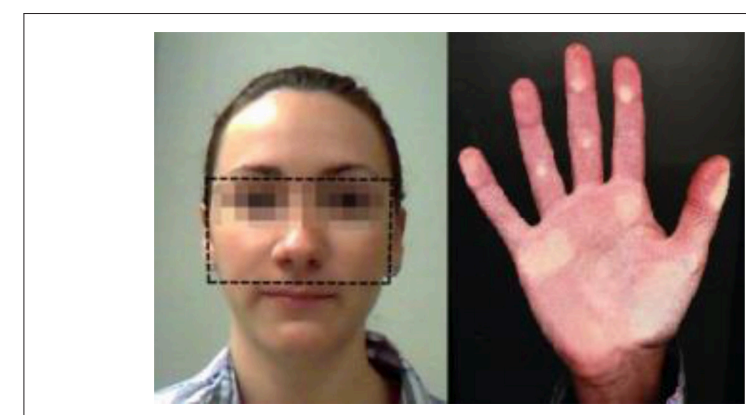

FIGURE 1 | An example of the ratio measurements.

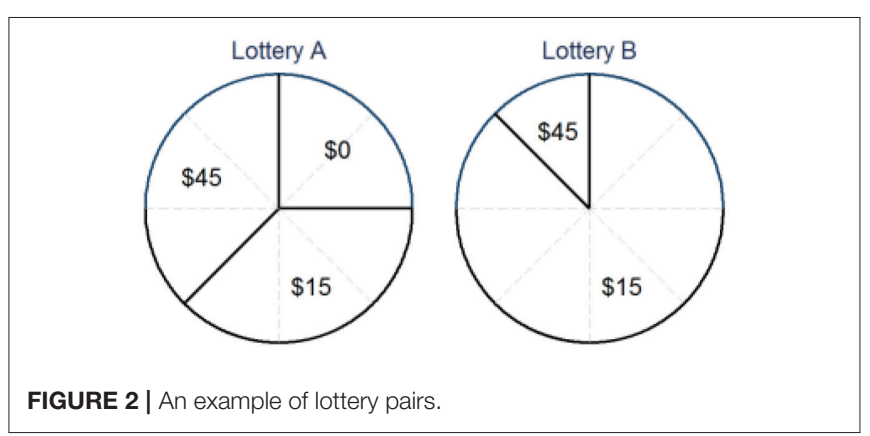

in Figure 2. In this example, Lottery A offers a $\$ 0$ prize with a probability of $25 \%, \$ 15$ with a probability of $37.5 \%$ and $\$ 45$ with a probability of $37.5 \%$, whilst Lottery B offers a $\$ 15$ prize with a probability of 87.5 and $\$ 45$ with a probability of $12.5 \%{ }^{3}$ Hence, the expected payoff is $\$ 22.5$ for Lottery A and $\$ 18.75$ for Lottery B. There were no numerical references to the probabilities and expected payoffs displayed; participants had to judge them from the pie chart within the given time constraint. No indifference choice was allowed between the two lotteries.

At the end of the 90 decisions, one lottery pair was randomly chosen and the participant's decision in this particular lottery pair was chosen. The "roulette wheel" of this lottery was then spun on their computer screen to determine their final payments. The instructions were explained in the form of a PowerPoint presentation before the start of the experiment, and they are shown in the Appendix.

\section{Estimation Procedure}

To study risk preferences, we fit a rank dependent utility model (RDU). We use this model because of its general form. It contains

with a point in the Marschak-Machina triangle (space representing all possible lotteries with three outcomes). In this triangle, EU decision makers have linear indifference curves. The selection of lotteries creates pairs of points in the triangle, by varying the location of these pairs of points, the choice among lotteries reveals the slopes of the indifference curves in the triangle and whether these slopes are not constant (revealing that decision makers violate EU, for instance because they weight probabilities).

${ }^{3}$ The lotteries used in each phase had different probabilities, however, they were drawn randomly from the same pool. They did not differ in characteristics on average. The number of lotteries in each phase (30 decisions) limits the risk of substantial differences across phase due to the random selection of lotteries. 
expected utility (EU) as a special case, allows us to disentangle risk preferences between a sensitivity to payoffs via the curvature of a utility function and a sensitivity to probabilities via the curvature of a probability weighting function (Wakker, 2010).

The utility of each lottery can be determined by the function:

$$
V=\sum_{k=1}^{K} w_{k} \times U_{k}
$$

Where

$$
\begin{cases}w_{i}=\omega\left(p_{i}+\cdots+p_{n}\right) & \\ -\omega\left(p_{i+1}+\cdots+p_{n}\right), & i=1, \ldots, n-1 \\ w_{i}=\omega\left(p_{i}\right), & i=n\end{cases}
$$

In the equations above, $k=1, \ldots, K$ and $K$ is the number of possible prizes in a lottery. The subscript of $w_{i}$ indicates that the prizes were ranked from the smallest to the biggest. The probability weighting function $\omega(p)$ is then applied to the aggregated probabilities, so the decision weights $w_{i}$ are derived by the differences in these transformed aggregated probabilities.

We use the power constant relative risk aversion (CRRA) utility function:

$$
U(x)=\frac{x^{1-\alpha}}{1-\alpha}
$$

where $x$ is each prize in a lottery and $\alpha(\neq 1)$ is the coefficient and yet to be estimated. If $\alpha>0$, it corresponded to a risk-averse attitude toward the actual payoff; $\alpha<0$ reflects a risk-loving attitude; $\alpha=0$ means risk-neutral.

Furthermore, we use the two-parameter weighting function in (Lattimore et al., 1992):

$$
\omega(p)=\frac{\delta p^{\gamma}}{\delta p^{\gamma}+(1-p)^{\gamma}}
$$

where $\delta, \gamma>0$. The parameter $\gamma$ determines the curvature (concavity or convexity) of the probability weighting. If $\gamma>1$, the function has an "S-shape." It means that a small probability is underweighted by the agent. For example, while in Figure 2, the probability to win $\$ 45$ is $12.5 \%$ in Lottery B, an agent would act as if he/she believed this probability is lower than $12.5 \%$. If $\gamma<1$ the function has an "inverse S-shape." It means that a small probability is over weighted. Then an agent thinks that his or her chance receiving $\$ 45$ is $>12.5 \%$.

The parameter $\delta$ provides an additional weight on the probability weighting function. If $\delta<1$, the probabilities are down weighted, indicating a pessimistic view of the payoffs. For example, an agent thinks that the chance of receiving $\$ 45$ is $<12.5 \%$ and that the chance of receiving $\$ 15$ is $<87.5 \%$. On the contrary, if $\delta>1$, the probabilities are over weighted, indicating that an agent holds an optimistic view toward the overall chances. Additionally, the EU is a special case when both $\gamma=\delta=1$.

We estimate these parameters using a random utility approach whereby the decision maker sometimes does not select the option with the highest utility due to cognitive errors. We use a "context utility" specification, making the variance of these cognitive errors depend on the magnitude of the payoffs being considered in the decision situation. This specification has been found to be better than alternatives which assume that errors are the same between different context of choice (Wilcox, 2011). The difference in utility between the two lotteries in a pair is modeled as:

$$
\nabla V=\frac{\lambda\left(V_{A}-V_{B}\right)}{U\left(z_{\max }\right)-U\left(z_{\min }\right)}
$$

where $\lambda$ represented the overall scale of the errors and the denominator is the influence of the specific context on the error in one lottery pair. The subscript of " $A$ " and " $B$ " represent the two lotteries and $z_{\text {max }}$ and $z_{\text {min }}$ denote the maximum and minimum possible payoffs in one pair.

The parameters $\alpha, \gamma, \delta$ as the reflection of participants' risk preference, and their perception of probabilities, are estimated by maximum likelihood method by using pooled data and clustering standard errors at each participant level. Therefore, the likelihood function is written as:

$$
\begin{aligned}
\ln L(\alpha, \gamma, \delta ; y)= & \sum_{m}\left(\left(\ln \Phi(\nabla V) \mid y_{m}=1\right)\right. \\
& \left.+\left(\ln (1-\Phi(\nabla V)) \mid y_{m}=0\right)\right)
\end{aligned}
$$

where $y_{m}=1(0)$ denotes the choice of lottery A (B) chosen in each pair $m$.

For ease of interpretation by the reader (and the authors), the $2 \mathrm{D}: 4 \mathrm{D}$ ratios were reversed as $\mathrm{R} 2 \mathrm{D}: 4 \mathrm{D}$, so that a higher ratio suggests higher testosterone exposure-just as higher fWHR suggests higher testosterone exposure. Both ratios are standardized. We also introduce two variables: "Male" as a gender dummy variable and "Time" as a categorical variable to measure the phases under three different time constraints. The parameters $\alpha, \gamma$ and $\delta$ are written as linear combination of variables, as written by the below equations, jointly in the maximum likelihood estimation:

$$
\begin{aligned}
\alpha= & \beta_{0}+\beta_{1} \text { Male }+\beta_{2} \text { Ratio }+\beta_{3} \text { Male } \times \text { Ratio }+\beta_{4} \text { Time } \\
& +\beta_{5} \text { Male } \times \text { Time }+\beta_{6} \text { Ratio } \times \text { Time } \\
& +\beta_{7} \text { Male } \times \text { Time } \times \text { Ratio } \\
\gamma= & \mu_{0}+\mu_{1} \text { Male }+\mu_{2} \text { Ratio }+\mu_{3} \text { Male } \times \text { Ratio }+\mu_{4} \text { Time } \\
& +\mu_{5} \text { Male } \times \text { Time }+\mu_{6} \text { Ratio } \times \text { Time } \\
& +\mu_{7} \text { Male } \times \text { Time } \times \text { Ratio } \\
\delta= & \varphi_{0}+\varphi_{1} \text { Male }+\varphi_{2} \text { Ratio }+\varphi_{3} \text { Male } \times \text { Ratio }+\varphi_{4} \text { Time } \\
& +\varphi_{5} \text { Male } \times \text { Time }+\varphi_{6} \text { Ratio } \times \text { Time } \\
& +\varphi_{7} \text { Male } \times \text { Time } \times \text { Ratio } .
\end{aligned}
$$

Therefore, our estimates are the parameters leading to the highest likelihood. After estimating our structural models from (1 to 6) jointly, we obtain two sets of estimations separately by using fWHR as "Ratio" (Estimation 1 in Table 2) and by using R2D:4D as "Ratio" (Estimation 2 in Table 2) in model (6). We can then investigate the interrelation between parameters and the effects of variables, by interpreting the coefficients for the sub-groups, for example, if $\beta_{3}$ is significantly not equal to 0 , it means the fWHR or 
TABLE 1 | Summary statistics.

\begin{tabular}{|c|c|c|c|c|c|}
\hline Subsample & Observations $(N)$ & fWHR & 2D:4D & $\begin{array}{l}\text { Expected return of chosen } \\
\text { lotteries }\end{array}$ & $\begin{array}{c}\text { Variance of chosen } \\
\text { lotteries }\end{array}$ \\
\hline Males & 80 & $\begin{array}{c}1.842 \\
(0.140)\end{array}$ & $\begin{array}{c}0.963 \\
(0.032)\end{array}$ & $\begin{array}{c}22.581 \\
(7.46)\end{array}$ & $\begin{array}{l}141.899 \\
(120.68)\end{array}$ \\
\hline Females & 74 & $\begin{array}{c}1.875 \\
(0.108)\end{array}$ & $\begin{array}{c}0.967 \\
(0.042)\end{array}$ & $\begin{array}{c}22.579 \\
(7.50)\end{array}$ & $\begin{array}{l}134.125 \\
(115.20)\end{array}$ \\
\hline $\begin{array}{l}\text { Mann-Whitney Test } \\
\left(H_{0}: \text { Females = Males }\right)\end{array}$ & & $\begin{array}{l}z=2.305 \\
p=0.021\end{array}$ & $\begin{array}{c}z=-1.548 \\
p=0.122\end{array}$ & $\begin{array}{c}z=-0.236 \\
p=0.814\end{array}$ & $\begin{array}{c}z=-3.263 \\
p=0.021\end{array}$ \\
\hline
\end{tabular}

Standard deviations are in the parentheses.

R2D:4D has significantly different effects on males and females' risk attitude in our experiment.

\section{RESULTS}

The summary statistics are presented in Table 1 . The average fWHR for male participants in our experiment is 1.842 ( $S D=$ $0.140)$, and the average for females is $1.875(S D=0.108)$. The fWHR is not normally distributed in our sample. Therefore, we use a nonparametric test, the Mann-Whitney test to examine the differences between two gender groups. We find that male participants have lower fWHR than females (test statistic: 2.305 and $p=0.021$ ). The average $2 \mathrm{D}: 4 \mathrm{D}$ ratio for males is 0.963 $(S D=0.032)$ and for females is $0.967(S D=0.042)$. However, the differences in 2D:4D ratio between male and female participants in our experiment are not significant (test statistic: -1.548 and $p=0.122$ ).

The expected return of chosen lotteries for males is 22.581 $(S D=7.46)$, showing no significant difference $(p=0.814)$ from females of $22.579(S D=7.50)$. However, females chose the lotteries with significantly $(p=0.021)$ lower variance $(134.125$, $S D=115.20)$ than males $(141.899, S D=120.68)$. This suggests that female participants in our experiment have less appetite for risk. We have also used the Brown and Forsythe (1974) to examine the equality of the variances of chosen lotteries. The test result suggests that male participants have higher variances, as the Levene's robust test statistic $\left(W_{0}\right)$ is 10.498 with $p=0.001$.

The CRRA function parameter $\alpha$ is separately estimated under EU and RDU. The EU model is simply estimated like the RDU model with the parameters $\gamma, \delta$ each set to 1 . Results for EU and RDU parameters are presented in Table 2.

We find that participants tend to have a concave utility function reflecting risk aversion $(\alpha>0)$, both in the EU and RDEU estimation. We also find that the probability weighting function displays the typical "inverse S-shape" with the parameter $\gamma$ being below 1 for men and women. These results are consistent with previous findings (Harrison and Rutström, 2008; Bruhin et al., 2010).

Q3: We find that males are less risk averse both in the EU and RDU estimations ( $\beta_{1}<0$ in Estimation 1 and 2 ). However, we do not find baseline gender differences in probability perception (the coefficients $\mu_{1}$ and $\varphi_{1}$ are not significantly different from 0 in Table 2). ${ }^{4}$

Q2 and Q3: There is some indication of a link between exposure and risk aversion. We find that R2D:4D has a negative effect on the risk-attitude parameter $\alpha$ only for males, but not for females ( $\beta_{3}$ in Estimation 2 is -0.164 and significant with $p$ $<0.05)$ in the EU estimations. It shows that males with higher R2D:4D have more appetite for risk (less risk-averse). We do not find an association between fWHR and any changes of risk taking $^{5}$ in the EU estimations ( $\beta_{2}$ in Estimation 1 and 2 are not significant).

In the RDU estimations, we find that $\mathrm{fWHR}$ ( $\beta_{2}$ is -0.037 with $p<0.1$ in Estimation 1) and R2D:4D ( $\beta_{2}$ is -0.037 with $p<0.05$ in Estimation 2) have a negative effect on females' risk-attitude, but positive effect on males' risk-attitude ( $\beta_{3}$ is 0.084 with $p<$ 0.01 and 0.069 with $p<0.1$ in Estimation 1 and 2 ). This suggests that females with higher ratios have more appetite for risk (less risk-averse), while the relationship is opposite for the males.

The differences in $\alpha$ across the two models are to be expected. The reason is that the risk attitudes are only represented by $\alpha$ in the EU model, while they are represented by $\alpha, \gamma$, and $\delta$ in the RDU model. In the case where EU is the best model, we should expect the RDU model to have a similar $\alpha$ and $\gamma=1, \delta=1$. Whenever people weight probabilities, $\gamma$ and $\delta$ are going to differ from 1 . In such a case, there is no reason to expect the $\alpha$ to be the same in the EU and RDU as the $\alpha$ in the EU will partially adjust itself to explain part of the risk attitudes reflected in the $\gamma$ and $\delta$ in the RDEU model.

There is a clearer indication of a link with the attitudes to probabilities for males (but not for female participants). The inverse S-shape of the probability weighting function is more pronounced for males with higher ratios ( $\mu_{3}$ is $-0.160, p<0.05$ in Estimation 1 and $-0.148, p<0.05$ in Estimation 2). And male participants with higher ratios are more optimistic $\left(\varphi_{3}\right.$ is 0.820 , $p<0.01$ in Estimation 1 and 0.945, $p<0.01$ in Estimation 2). It suggests that male participants with higher ratios overweight their chances of receiving bigger payoffs and are more optimistic

\footnotetext{
${ }^{4}$ Note that gender differences can still exist overall due to gender differences in other variables such as prenatal exposure to testosterone which can have an influence on risk preferences. We look into this below.

${ }^{5}$ The $\beta_{3}$ in Estimation 1 is -0.115 , but not significant as $p>0.1$ in the EU estimations.
} 
TABLE 2 | Estimation Results on $\mathrm{WWHR}$ and R2D:4D.

\begin{tabular}{|c|c|c|c|c|c|c|c|c|c|}
\hline \multirow[t]{2}{*}{ Estimation 1} & \multirow{2}{*}{$\begin{array}{c}\mathbf{E U} \\
\alpha\end{array}$} & \multicolumn{3}{|c|}{ RDU } & \multirow[t]{2}{*}{ Estimation 2} & \multirow{2}{*}{$\begin{array}{c}\text { EU } \\
\alpha\end{array}$} & \multicolumn{3}{|c|}{ RDU } \\
\hline & & $\alpha$ & $\gamma$ & $\delta$ & & & $\alpha$ & $\gamma$ & $\delta$ \\
\hline $\begin{array}{l}\text { Male } \\
\left(\beta_{1}, \beta_{1}, \mu_{1}, \varphi_{1}\right)\end{array}$ & $\begin{array}{l}-0.135^{\star \star} \\
(-2.37)\end{array}$ & $\begin{array}{l}-0.071^{\star \star *} \\
(-2.60)\end{array}$ & $\begin{array}{l}0.059 \\
(1.01)\end{array}$ & $\begin{array}{l}0.316 \\
(1.31)\end{array}$ & $\begin{array}{l}\text { Male } \\
\left(\beta_{1}, \beta_{1}, \mu_{1}, \varphi_{1}\right)\end{array}$ & $\begin{array}{c}-0.096^{\star \star} \\
(-2.12)\end{array}$ & $\begin{array}{c}-0.075^{\text {** }} \\
(-2.50)\end{array}$ & $\begin{array}{l}0.054 \\
(0.94)\end{array}$ & $\begin{array}{l}0.108 \\
(0.59)\end{array}$ \\
\hline $\begin{array}{l}\text { fWHR } \\
\left(\beta_{2}, \beta_{2}, \mu_{2}, \varphi_{2}\right)\end{array}$ & $\begin{array}{l}-0.026 \\
(-0.79)\end{array}$ & $\begin{array}{l}-0.037^{\star} \\
(-1.79)\end{array}$ & $\begin{array}{l}0.067 \\
(1.32)\end{array}$ & $\begin{array}{l}-0.026 \\
(-0.14)\end{array}$ & $\begin{array}{l}\text { R2D:4D } \\
\left(\beta_{2}, \beta_{2}, \mu_{2}, \varphi_{2}\right)\end{array}$ & $\begin{array}{l}-0.021 \\
(-0.76)\end{array}$ & $\begin{array}{l}-0.037^{\star \star} \\
(-2.09)\end{array}$ & $\begin{array}{l}0.038 \\
(1.52)\end{array}$ & $\begin{array}{l}-0.068 \\
(-0.39)\end{array}$ \\
\hline $\begin{array}{l}\text { Male } \times \text { fWHR } \\
\left(\beta_{3}, \beta_{3}, \mu_{3}, \varphi_{3}\right)\end{array}$ & $\begin{array}{l}-0.115 \\
(-1.64)\end{array}$ & $\begin{array}{c}0.084^{\star \star \star} \\
(2.97)\end{array}$ & $\begin{array}{c}-0.160^{\star *} \\
(-2.41)\end{array}$ & $\begin{array}{c}0.820^{\star \star \star} \\
(3.35)\end{array}$ & $\begin{array}{l}\text { Male } \times \text { R2D:4D } \\
\left(\beta_{3}, \beta_{3}, \mu_{3}, \varphi_{3}\right)\end{array}$ & $\begin{array}{c}-0.164^{\star \star} \\
(-2.19)\end{array}$ & $\begin{array}{l}0.069^{*} \\
(1.80)\end{array}$ & $\begin{array}{c}-0.148^{\star \star} \\
(-2.38)\end{array}$ & $\begin{array}{c}0.945^{\star \star \star} \\
(3.24)\end{array}$ \\
\hline $\begin{array}{l}\text { Under } 8 \mathrm{~s} \\
\left(\beta_{4}, \beta_{4}, \mu_{4}, \varphi_{4}\right)\end{array}$ & $\begin{array}{c}-0.183^{\star \star \star} \\
(-5.78)\end{array}$ & $\begin{array}{l}-0.085^{\star \star \star} \\
(-2.82)\end{array}$ & $\begin{array}{l}-0.303^{\star \star \star} \\
(-7.84)\end{array}$ & $\begin{array}{l}-0.373^{\star \star \star} \\
(-3.00)\end{array}$ & $\begin{array}{l}\text { Under } 8 \mathrm{~s} \\
\left(\beta_{4}, \beta_{4}, \mu_{4}, \varphi_{4}\right)\end{array}$ & $\begin{array}{l}-0.167^{\star \star *} \\
(-5.47)\end{array}$ & $\begin{array}{l}-0.088^{\star \star} \\
(-2.22)\end{array}$ & $\begin{array}{c}-0.297^{\star \star \star} \\
(-6.34)\end{array}$ & $\begin{array}{l}-0.364^{\star \star \star} \\
(-2.90)\end{array}$ \\
\hline $\begin{array}{l}\text { Under } 4 \mathrm{~s} \\
\left(\beta_{4}, \beta_{4}, \mu_{4}, \varphi_{4}\right)\end{array}$ & $\begin{array}{l}-0.045 \\
(-1.19)\end{array}$ & $\begin{array}{l}-0.020 \\
(-0.64)\end{array}$ & $\begin{array}{l}-0.157^{\star \star \star} \\
(-2.93)\end{array}$ & $\begin{array}{l}-0.119 \\
(-0.78)\end{array}$ & $\begin{array}{l}\text { Under } 4 \mathrm{~s} \\
\left(\beta_{4}, \beta_{4}, \mu_{4}, \varphi_{4}\right)\end{array}$ & $\begin{array}{l}-0.024 \\
(-0.61)\end{array}$ & $\begin{array}{l}-0.025 \\
(-0.66)\end{array}$ & $\begin{array}{c}-0.149^{\star \star \star} \\
(-2.69)\end{array}$ & $\begin{array}{l}-0.168 \\
(-1.03)\end{array}$ \\
\hline $\begin{array}{l}\text { Male } \times \text { Under } 8 \mathrm{~s} \\
\left(\beta_{5}, \beta_{5}, \mu_{5}, \varphi_{5}\right)\end{array}$ & $\begin{array}{l}0.017 \\
(0.25)\end{array}$ & $\begin{array}{l}-0.043 \\
(-0.70)\end{array}$ & $\begin{array}{l}-0.035 \\
(-0.57)\end{array}$ & $\begin{array}{l}-0.328 \\
(-1.58)\end{array}$ & $\begin{array}{l}\text { Male } \times \text { Under } 8 \mathrm{~s} \\
\left(\beta_{5}, \beta_{5}, \mu_{5}, \varphi_{5}\right)\end{array}$ & $\begin{array}{l}-0.014 \\
(-0.25)\end{array}$ & $\begin{array}{l}-0.010 \\
(-0.03)\end{array}$ & $\begin{array}{l}-0.031 \\
(-0.25)\end{array}$ & $\begin{array}{l}-0.112 \\
(-0.23)\end{array}$ \\
\hline $\begin{array}{l}\text { Male } \times \text { Under } 4 \mathrm{~s} \\
\left(\beta_{5}, \beta_{5}, \mu_{5}, \varphi_{5}\right)\end{array}$ & $\begin{array}{l}0.007 \\
(0.10)\end{array}$ & $\begin{array}{l}0.052 \\
(1.10)\end{array}$ & $\begin{array}{l}-0.062 \\
(-0.83)\end{array}$ & $\begin{array}{l}0.049 \\
(0.19)\end{array}$ & $\begin{array}{l}\text { Male } \times \text { Under } 4 \mathrm{~s} \\
\left(\beta_{5}, \beta_{5}, \mu_{5}, \varphi_{5}\right)\end{array}$ & $\begin{array}{l}0.008 \\
(0.13)\end{array}$ & $\begin{array}{l}0.064 \\
(1.25)\end{array}$ & $\begin{array}{l}-0.064 \\
(-0.88)\end{array}$ & $\begin{array}{l}0.075 \\
(0.32)\end{array}$ \\
\hline $\begin{array}{l}\mathrm{fWHR} \times \text { Under } 8 \mathrm{~s} \\
\left(\beta_{6}, \beta_{6}, \mu_{6}, \varphi_{6}\right)\end{array}$ & $\begin{array}{l}0.084^{\star \star} \\
(2.22)\end{array}$ & $\begin{array}{l}-0.032 \\
(-1.17)\end{array}$ & $\begin{array}{l}0.034 \\
(0.75)\end{array}$ & $\begin{array}{l}-0.051 \\
(-0.32)\end{array}$ & $\begin{array}{l}\text { R2D:4D } \times \text { Under } 8 \mathrm{~s} \\
\left(\beta_{6}, \beta_{6}, \mu_{6}, \varphi_{6}\right)\end{array}$ & $\begin{array}{l}0.064 \\
(1.52)\end{array}$ & $\begin{array}{l}-0.032 \\
(-1.29)\end{array}$ & $\begin{array}{l}0.014 \\
(0.57)\end{array}$ & $\begin{array}{l}-0.073 \\
(-0.46)\end{array}$ \\
\hline $\begin{array}{l}\text { fWHR } \times \text { Under } 4 \mathrm{~s} \\
\left(\beta_{6}, \beta_{6}, \mu_{6}, \varphi_{6}\right)\end{array}$ & $\begin{array}{c}0.108^{\star \star \star} \\
(2.78)\end{array}$ & $\begin{array}{l}-0.008 \\
(-0.25)\end{array}$ & $\begin{array}{l}0.052 \\
(0.72)\end{array}$ & $\begin{array}{l}-0.276 \\
(-1.59)\end{array}$ & $\begin{array}{l}\text { R2D:4D } \times \text { Under } 4 \mathrm{~s} \\
\left(\beta_{6}, \beta_{6}, \mu_{6}, \varphi_{6}\right)\end{array}$ & $\begin{array}{l}0.058^{\star} \\
(1.71)\end{array}$ & $\begin{array}{l}-0.003 \\
(-0.06)\end{array}$ & $\begin{array}{l}0.042 \\
(1.23)\end{array}$ & $\begin{array}{l}-0.147 \\
(-0.48)\end{array}$ \\
\hline $\begin{array}{l}\text { Male } \times \text { fWHR } \times \text { Under } 8 \mathrm{~s} \\
\left(\beta_{7}, \beta_{7}, \mu_{7}, \varphi_{7}\right)\end{array}$ & $\begin{array}{c}-0.158^{*} \\
(-1.76)\end{array}$ & $\begin{array}{l}-0.067 \\
(-0.97)\end{array}$ & $\begin{array}{l}-0.032 \\
(-0.46)\end{array}$ & $\begin{array}{l}-0.650^{\star * *} \\
(-2.97)\end{array}$ & $\begin{array}{l}\text { Male } \times \text { R2D:4D } \times \text { Under } \\
8 \mathrm{~s} \\
\left(\beta_{7}, \beta_{7}, \mu_{7}, \varphi_{7}\right)\end{array}$ & $\begin{array}{l}-0.288^{\star \star \star} \\
(-2.68)\end{array}$ & $\begin{array}{l}-0.097 \\
(-0.11)\end{array}$ & $\begin{array}{l}-0.031 \\
(-0.07)\end{array}$ & $\begin{array}{l}-0.558 \\
(-0.59)\end{array}$ \\
\hline $\begin{array}{l}\text { Male } \times \text { fWHR } \times \text { Under 4s } \\
\left(\beta_{7}, \beta_{7}, \mu_{7}, \varphi_{7}\right)\end{array}$ & $\begin{array}{l}-0.162^{\star \star} \\
(-1.99)\end{array}$ & $\begin{array}{l}0.057 \\
(1.49)\end{array}$ & $\begin{array}{l}-0.027 \\
(-0.32)\end{array}$ & $\begin{array}{l}0.378^{\star} \\
(1.69)\end{array}$ & $\begin{array}{l}\text { Male } \times \text { R2D:4D } \times \text { Under } \\
4 \mathrm{~s} \\
\left(\beta_{7}, \beta_{7}, \mu_{7}, \varphi_{7}\right)\end{array}$ & $\begin{array}{l}-0.169 \\
(-1.37)\end{array}$ & $\begin{array}{l}0.029 \\
(0.44)\end{array}$ & $\begin{array}{l}-0.028 \\
(-0.44)\end{array}$ & $\begin{array}{l}-0.011 \\
(-0.03)\end{array}$ \\
\hline $\begin{array}{l}\text { Constant } \\
\left(\beta_{0}, \beta_{0}, \mu_{0}, \varphi_{0}\right)\end{array}$ & $\begin{array}{l}0.480^{\star \star \star} \\
(15.43)\end{array}$ & $\begin{array}{c}0.558^{\star \star \star} \\
(33.68)\end{array}$ & $\begin{array}{l}0.844^{\star \star \star} \\
(20.54)\end{array}$ & $\begin{array}{l}1.394^{\star \star \star} \\
(10.31)\end{array}$ & $\begin{array}{l}\text { Constant } \\
\left(\beta_{0}, \beta_{0}, \mu_{0}, \varphi_{0}\right)\end{array}$ & $\begin{array}{l}0.476^{\star \star \star} \\
(15.70)\end{array}$ & $\begin{array}{l}0.549^{\star \star \star} \\
(34.80)\end{array}$ & $\begin{array}{l}0.853^{\star \star \star} \\
(18.18)\end{array}$ & $\begin{array}{l}1.381^{\star \star \star} \\
(11.19)\end{array}$ \\
\hline
\end{tabular}

$Z$ statistics in parentheses, ${ }^{\star} p<0.1,{ }^{\star *} p<0.05,{ }^{\star \star \star} p<0.01$.

toward their chances of winning monetary outcomes. A similar association was not found for female participants.

Q1: We find some indication that time pressure increases risk aversion with $\alpha$ being smaller in the $8 \mathrm{~s}$ time pressure condition $\left(\beta_{4}\right.$ is -0.183 with $p<0.01$ and -0.167 with $p<0.01$ in Estimation 1 and 2). This result is in line with previous findings (Kocher and Sutter, 2006). However, we do not find an overall significant effect in our extreme time pressure condition (4s).

There is also a clear effect of time pressure on the probability weighting parameter. The "inverse S-shape" appears more pronounced in the time pressure conditions $\left(\mu_{4}\right.$ is -0.303 with $p$ $<0.01$ for $8 \mathrm{~s}$ and -0.157 with $p<0.01$ for $4 \mathrm{~s}$ in Estimation 1; $\mu_{4}$ is -0.297 with $p<0.01$ for $8 \mathrm{~s}$ and -0.149 with $p<0.01$ for $4 \mathrm{~s}$ in Estimation 2). We also find more optimism, but only in the $8 \mathrm{~s}$ time pressure condition $\left(\varphi_{4}\right.$ is -0.373 with $p<0.01$ and -0.364 with $p<0.01$ for $8 \mathrm{~s}$ in Estimations 1 and 2).

Q1 and Q3: However, we do not find notable baseline gender differences in risk attitude under time pressure (8 and $4 \mathrm{~s}$ conditions), as $\beta_{5}, \mu_{5}$ and $\varphi_{5}$ are not significantly different from zero in Estimation 1 and $2 .^{6}$

Q1, Q2, and Q3: When looking at the coefficient of risk aversion, there is a differential effect of time pressure by gender

\footnotetext{
${ }^{6}$ Gender differences in risk attitude under time pressure can still be present due to
} gender differences in prenatal exposure to testosterone. We look into this below. as a function of fWHR in the $8 \mathrm{~s}$ time pressure condition $\left(\beta_{6}\right.$ is 0.084 with $p<0.05$ while $\beta_{7}$ is -0.158 and marginally significant with $p<0.1$ in Estimation 1). In the phase with extreme time pressure, we also find that female participants with higher fWHR have more risk-averse attitude, while males with higher ratios have more appetite for risk ( $\beta_{6}$ is 0.108 with $p<0.01$ while $\beta_{7}$ is -0.162 with $p<0.05$ in Estimation 1). Further, in the Estimation 2 , we find that female participants with higher R2D:4D have more risk-averse attitude in the $4 \mathrm{~s}$ time pressure condition $\left(\beta_{6}\right.$ is 0.058 and marginally significant with $p<0.1$ ), whereas males with higher R2D:4D have more appetite for risk in the $8 \mathrm{~s}$ time pressure condition $\left(\beta_{7}\right.$ is -0.288 with $p<0.01$ ).

The previous results decompose the effect on risk attitudes and probability perception of gender, prenatal exposure and time pressure. Once this decomposition is done, we can look into how different subgroups differ. We present here our estimation of the parameters $\alpha$ (see Figure 3), $\gamma$ and $\delta$ (see Figure 4) at the aggregated level for meaningful subgroups for the fWHR ratios (overall, similar results are found for 2D:4D).

In terms of sensitivity to outcomes, the male subgroup with higher fWHR shows less curvature under time pressure in their utility function than that with lower ratios (see right column in Figure 3), but similar association is not found in female subgroup (see left column in Figure 3). The curvature in utility suggests that the risk attitude of an agent: concave as risk-averse $\alpha>0$; 


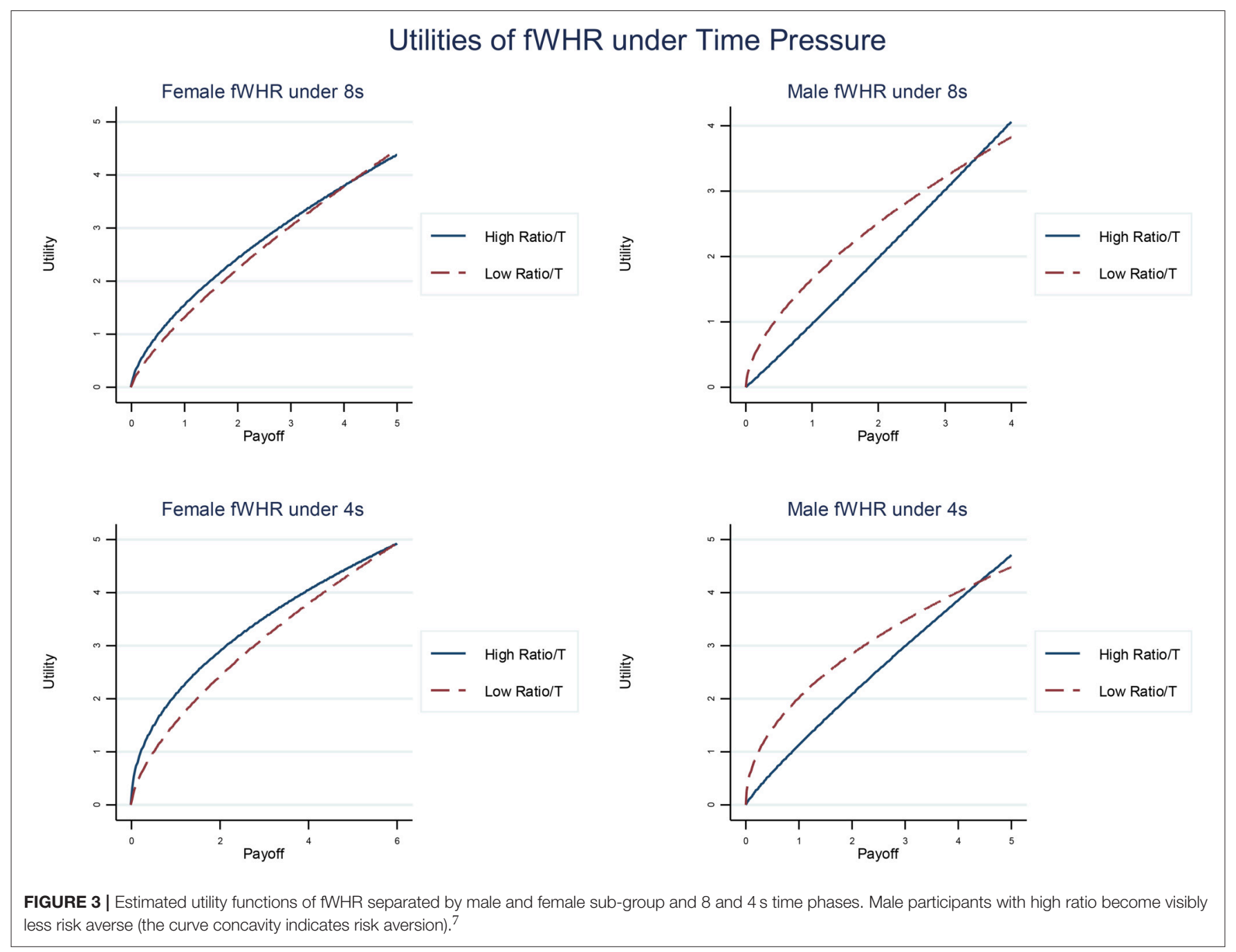

convex as risk-loving $\alpha<0$. Less curvature in utility function suggests more appetite for risk.

As the prizes in the lottery are rearranged from the biggest to the smallest in a rank-dependent manner, the left bottom region in a probability weighting function reveals if the probabilities of the prizes are over weighted or under weighted. For example, in any subfigure in Figure 4, the estimated functions are above the diagonal line in the left bottom region. It means that the actual probabilities are over weighted.

In terms of sensitivity to probability, under time pressure, males, with higher fWHR overestimate probabilities (Figure 4) of receiving bigger payoffs and have a more optimistic view

\footnotetext{
${ }^{7} \mathrm{We}$ calculate the utilities based on our estimations of Estimation 1 and 2 in Table 2. As fWHR and R2D:4D are standardized, we use value of 1 as high ratio and -1 as low ratio. Therefore, for example, the utility for females with high ratios in the 8 s time condition is calculated as: $\alpha=0.480-0.026 \times 1-0.183+0.084 \times 1=$ 0.355 , and the utility for low ratios is 0.239 . The utilities for males in the 8 s time condition are calculated as -0.036 for high ratios and 0.395 for low ratios. The utilities for females in the $4 \mathrm{~s} \mathrm{time} \mathrm{condition} \mathrm{are} \mathrm{calculated} \mathrm{are} 0.517$ for high ratios and 0.354 for low ratios, and that for males are 0.112 for high ratios and 0.503 for low ratios.
}

about probabilities than those with lower ratios. However, we observe the opposite effect in the female sub-group (see left column in Figure 4). These effects are more pronounced under extreme time pressure (by comparing the top and bottom rows in Figure 4).

To answer our Questions 1-3 in section Motivations and Hypothesesdirectly, the equations (6) in our structural models are also estimated by using: (1) firstly, the "Time" variable, which is a categorical variable to measure the phases under three different time constraints, as covariates; (2) then adding "Male" and "Ratio" variables into the covariates; (3) finally, adding the interactions in to the covariates. The EU estimates are shown in Table 3 in Appendix (Supplementary Material) and the RDU estimates are shown in Tables 4, 5 in Appendix (Supplementary Material).

Based on our findings discussed above, we can now answer the three questions raised in section Motivations and Hypotheses and summarize our results:

Result 1: Time pressure increases an appetite for risk. Participants under time pressure become more optimistic. 


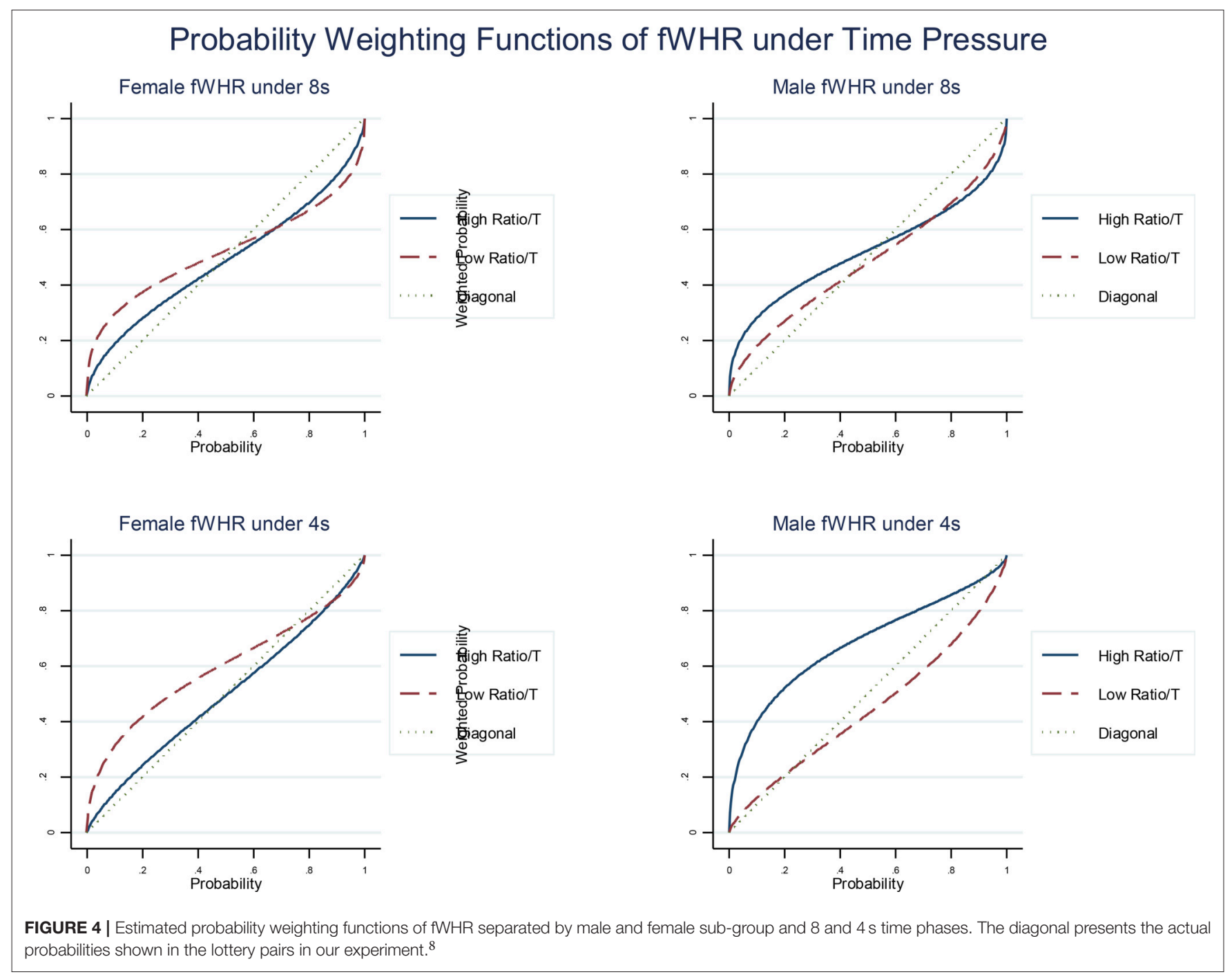

Result 2: We do not find enough evidence to support the hypothesis that higher testosterone exposure is associated with higher risk-taking. We observed mixed results in EU and RDU estimates.

Result 3: We find that male participants are less risk averse and that the gender gap in risk attitudes increases under moderate time pressure. We also observe that men with higher testosterone exposure exhibit a greater optimism and overestimation of small probabilities of success.

\section{DISCUSSION AND CONCLUSION}

This study looked into gender difference in risk attitude under pressure and the potential role of prenatal exposure. We find that males are less risk averse than female participants, in line with existing research. We disentangled the different aspects of risk preferences, giving us new insights into these gender differences.

${ }^{8}$ The calculations of the probability weighting functions apply the same method of calculations in the utilities in Figure 3.
We found that gender differences were clearer in the sensitivity to probability than in the sensitivity to outcomes.

When looking at prenatal exposure to testosterone, we find that males with high fWHR and R2D:4D sought more risk and overweighted small probabilities of high gain. They also were more optimistic about outcomes than the females. Females with high fWHR and R2D:4D did the opposite, taking less risk. Time pressure also, on average, made males more optimistic.

In summary, men, and particularly those with high fWHR and R2D:4D took more risk and were more bullish about pursuing an elusive chance of winning, especially under time pressure.

These results show that prenatal testosterone exposure alters risk-taking in men; particularly under time pressure. Previous research has shown that a low 2D:4D (or high $\mathrm{R} 2 \mathrm{D}: 4 \mathrm{D}$ ) ratio associated with high testosterone exposure predicted a longer survival of professional traders (Coates and Page, 2009). As a consequence, men with a low $2 \mathrm{D}: 4 \mathrm{D}$ ratio were likely to be overrepresented in the population of traders. Our result 
may help make sense of this finding given that the male participants with low 2D:4D ratios displayed a greater propensity to take risks under time pressure. The results of the present research did not find such an effect of time pressure on women. If women traders are seen as taking fewer risks than their male counterparts, particularly in response to time pressure, then, in a market which values activity, they may be seen as less appropriate candidates. Moreover, if they make it past the selection phase, they may well not be retained as they do not measure up to the accepted yardstick for performance.

As well as demonstrating marked differences between men and women in decision making, this research also clearly confirms that preferences are not stable and that time pressure affects choice. Because each participant was exposed to the same information in each case, there was no information difference. Rather time pressure was likely to have, interfered with information processing, thereby producing differing results. The nature of this instability was complex, being influenced by both time pressure and the long-term organizational effects of testosterone. Previous experimental and theoretical studies have argued that deliberation may have a non-linear effect on moral choices (Moore and Tenbrunsel, 2014) and cooperation (Capraro and Cococcioni, 2016). A non-linear relationship has also be observed by some authors between circulating testosterone and risk taking (Stanton et al., 2011). The consequence of all this is that the useful simplification of assuming that preferences are stable, may lead to forget the fact that preference instability is substantial, widespread and non-linear.

Our results suggest that if the market privileges risk taking and confidence under time pressure then a combination of physiological predisposition and preference instability may favor the employment of men. This, in turn, may explain the preponderance of men in the market. This is difficult to prove in any definitive sense as counterfactuals are not readily available. Care also has to be taken in extrapolating from a laboratory study to global markets as the requirements of controlling for factors except those under investigation inevitably means that a degree of verisimilitude is lost. The risk-taking task, for example is a stylized one with a limited number of parameters. The sample size, relative to financial markets, is small, and does not, necessarily, mirror the profile of those in financial markets. Moreover, the choices are single shot interactions, rather than the dynamic, ongoing and varied interactions observed in real markets. This study only looks at the organizational effects of testosterone manifest in $2 \mathrm{D}: 4 \mathrm{D}$ ratio and fWHR, not at the activational effects of circulating testosterone. It also does not address other hormones, such as cortisol, which have been demonstrated to affect risk-taking (Kandasamy et al., 2014). Despite this, our findings on gender differences, the role of prenatal testosterone exposure and of time pressure provide some clues as to why women may be at a perceived disadvantage in a pressurized trading environment. This, in turn, may mean that they are less likely to be recruited and retained.

To provide a fuller picture, there are a number of questions for further research to address. The first is to examine risk taking when the probability distribution is less clearly defined. This ambiguity may affect the results. The second question is whether the nature of risk taking changes when there is interaction between participants. These sorts of interaction studies have been undertaken in hormone research (e.g., Cueva et al., 2015). They improve external validity but sometimes at the expense of mechanistic clarity. Third, external validity could be improved by conducting the task with different groups of bank employees. It may be that different functions have different risk profiles, so traders may differ from asset managers, for example. Fourth, further research should sample circulating hormone levels to explore the interaction between activational (circulating) and organizational (i.e., those shaping development) hormones.

This research provides a piece of the puzzle as to why women are underrepresented in a number of areas of finance. But does it matter that these areas are male dominated? Markets are wellserved by diversity as a means of tempering herd instincts. A market that is skewed in favor of employing men may, therefore, bring its own set of problems. Some researchers, for example, Coates and colleagues (Coates et al., 2010), have suggested that improving gender diversity may improve market stability. This is supported by experimental evidence which suggested both gender (Cueva and Rustichini, 2015) and hormonal diversity (Cueva et al., 2015) improve market stability. Although there are many explanations for aggregate behavior in financial markets, the effect of gender, preference stability and hormonal exposure may have significant repercussions.

\section{ETHICS STATEMENT}

This study was carried out in accordance with the recommendations of the ethics committee from School of Economics and Finance at Queensland University of Technology with written informed consent from all subjects. All subjects gave written informed consent in accordance with the Declaration of Helsinki. The protocol was approved by the ethics committee from School of Economics and Finance at Queensland University of Technology.

\section{AUTHOR CONTRIBUTIONS}

All authors listed have made a substantial, direct and intellectual contribution to the work, and approved it for publication.

\section{SUPPLEMENTARY MATERIAL}

The Supplementary Material for this article can be found online at: https://www.frontiersin.org/articles/10.3389/fnbeh. 2017.00246/full\#supplementary-material 


\section{REFERENCES}

Aguiar, F., Brañas-Garza, P., Cobo-Reyes, R., Jimenez, N., and Miller, L. M. (2009). Are women expected to be more generous? Exp. Econ. 12, 93-98. doi: 10.1007/s10683-008-9199-Z

Archer, J. (2006). Testosterone and human aggression: an evaluation of the challenge hypothesis. Neurosci. Biobehav. Rev. 30, 319-345. doi: 10.1016/j.neubiorev.2004.12.007

Austin, E. J., Manning, J. T., Mcinroy, K., and Mathews, E. (2002). A preliminary investigation of the associations between personality, cognitive ability and digit ratio. Pers. Individ. Diff. 33, 1115-1124. doi: 10.1016/S0191-8869(02)00002-8

Barber, B. M., and Odean, T. (2001). Boys will be boys: gender, overconfidence, and common stock investment. Q. J. Econ. 116, 261-292. doi: 10.1162/003355301556400

Barel, E. (2017). 2D:4D, optimism, and risk taking. Curr. Psychol. 1-9. doi: $10.1007 /$ s12144-017-9598-4

Bosch-Domènech, A., Brañas-Garza, P., and Espín, A. M. (2014). Can exposure to prenatal sex hormones (2D:4D) predict cognitive reflection? Psychoneuroendocrinology 43, 1-10. doi: 10.1016/j.psyneuen.2014.01.023

Brañas-Garza, P., and Rustichini, A. (2011). Organizing effects of testosterone and economic behavior: not just risk taking. PLoS ONE 6:e29842. doi: 10.1371/journal.pone.0029842

Brañas-Garza, P., Capraro, V., and Rascon, E. (2016). Gender Differences in Altruism: Expectations, Actual Behaviour and Accuracy of Beliefs. Available online at: https://ssrn.com/abstract=2796221

Brañas-Garza, P., Galizzi, M., and Nieboer, J. (2017). Experimental and selfreported measures of risk taking and digit ratio (2D: 4D): evidence from a large, systematic study. Int. Econ. Rev.

Breedlove, S. M., and Hampson, E. (2002). "Sexual differentiation of the brain and behavior," in Behavioral Endocrinology, 2nd Edn., eds J. B. Becker, S. M. Breedlove, D. Crews, and M. M. Mccarthy (Cambridge, MA; London: MIT Press), 776.

Brown, M. B., and Forsythe, A. B. (1974). Robust tests for the equality of variances. J. Am. Stat. Assoc. 69, 364-367. doi: 10.1080/01621459.1974.10482955

Bruhin, A., Fehr-Duda, H., and Epper, T. (2010). Risk and rationality: uncovering heterogeneity in probability distortion. Econometrica 78, 1375-1412. doi: 10.3982/ECTA7139

Busse, J. A., and Green, T. C. (2002). Market efficiency in real time. J. Finan. Econ. 65, 415-437. doi: 10.1016/S0304-405X(02)00148-4

Byrnes, J. P., Miller, D. C., and Schafer, W. D. (1999). Gender differences in risk taking: a meta-analysis. Psychol. Bull. 125, 367-383. doi: 10.1037/0033-2909.125.3.367

Capraro, V., and Cococcioni, G. (2016). Rethinking spontaneous giving: extreme time pressure and ego-depletion favor self-regarding reactions. Sci. Rep. 6:27219. doi: 10.1038/srep27219

Capraro, V., and Cococcioni, G. (2015). Social setting, intuition and experience in laboratory experiments interact to shape cooperative decision-making. Proc. $R$. Soc. B 282:20150237. doi: 10.1098/rspb.2015.0237

Capraro, V., Corgnet, B., Espín, A. M., and Hernán-González, R. (2017). Deliberation favours social efficiency by making people disregard their relative shares: evidence from USA and India. R. Soc. Open Sci. 4:160605. doi: 10.1098/rsos.160605

Carré, J. M., and McCormick, C. M. (2008). In your face: facial metrics predict aggressive behaviour in the laboratory and in varsity and professional hockey players. Proc. R. Soc. Lond. B Biol. Sci. 275, 2651-2656. doi: 10.1098/rspb.2008. 0873

Catalyst, I. (2016). Women in Accounting [Online]. Catalyst, Inc., Available online at: http://www.catalyst.org/knowledge/women-accounting-footnote4_zipkayp (Accessed Oct 18, 2017).

Chambers Partners, L. (2014). Law Firm Gender Diversity [Online]. Chambers Partners, Ltd. Available online at: http://www.chambersstudent.co.uk/ where-to-start/newsletter/2014-gender-in-the-law-survey/law-firm-genderdiversity (Accessed Oct 18, 2017).

Charness, G., and Rustichini, A. (2011). Gender differences in cooperation with group membership. Games Econ. Behav. 72, 77-85. doi: 10.1016/j.geb.2010.07.006

Coates, J. M., and Page, L. (2009). A note on trader sharpe ratios. PLoS ONE 4:e8036. doi: 10.1371/journal.pone.0008036
Coates, J. M., Gurnell, M., and Rustichini, A. (2009). Second-to-fourth digit ratio predicts success among high-frequency financial traders. Proc. Natl. Acad. Sci. U.S.A. 106, 623-628. doi: 10.1073/pnas.0810907106

Coates, J. M., Gurnell, M., and Sarnyai, Z. (2010). From molecule to market: steroid hormones and financial risk-taking. Philos. Trans. R. Soc. Lond. B Biol. Sci. 365, 331-343. doi: 10.1098/rstb.2009.0193

Conte, A., Hey, J. D., and Moffatt, P. G. (2011). Mixture models of choice under risk. J. Econometr. 162, 79-88. doi: 10.1016/j.jeconom.2009.10.011

Croson, R., and Gneezy, U. (2009). Gender differences in preferences. J. Econ. Lit. 47, 448-474. doi: 10.1257/jel.47.2.448

Cueva, C., and Rustichini, A. (2015). Is financial instability male-driven? gender and cognitive skills in experimental asset markets. J. Econ. Behav. Organ. 119, 330-344. doi: 10.1016/j.jebo.2015.08.014

Cueva, C., Roberts, R. E., Spencer, T., Rani, N., Tempest, M., Tobler, P. N., et al. (2015). Cortisol and testosterone increase financial risk taking and may destabilize markets. Sci. Rep. 5:11206. doi: 10.1038/srep11206

Dalton, P., and Ghosal, S. (2014). Self-Confidence, Overconfidence and Prenatal Testosterone Exposure: Evidence from the Lab. Scottish Institute for Research in Economics.

De Paola, M., and Gioia, F. (2016). Who performs better under time pressure? results from a field experiment. J. Econ. Psychol. 53, 37-53. doi: 10.1016/j.joep.2015.12.002

Deaves, R., Lüders, E., and Schröder, M. (2010). The dynamics of overconfidence: evidence from stock market forecasters. J. Econ. Behav. Organ. 75, 402-412. doi: 10.1016/j.jebo.2010.05.001

Drichoutis, A. C., and Nayga, R. M. (2015). Do risk and time preferences have biological roots? South. Econ. J. 82, 235-256. doi: 10.4284/0038-4038-2 013.246

Eckel, C. C., and Füllbrunn, S. C. (2015). Thar she blows? Gender, competition, and bubbles in experimental asset markets. Am. Econ. Rev. 105, 906-920. doi: 10.1257/aer.20130683

Eckel, C. C., and Grossman, P. J. (2002). Sex differences and statistical stereotyping in attitudes toward financial risk. Evol. Hum. Behav. 23, 281-295. doi: 10.1016/S1090-5138(02)00097-1

Fellner, G., and Maciejovsky, B. (2007). Risk attitude and market behavior: evidence from experimental asset markets. J. Econ. Psychol. 28, 338-350. doi: 10.1016/j.joep.2007.01.006

Fink, B., Neave, N., and Seydel, H. (2007). Male facial appearance signals physical strength to women. Am. J. Hum. Biol. 19, 82-87. doi: 10.1002/ajhb.20583

Fink, B., Neave, N., Laughton, K., and Manning, J. T. (2006). Second to fourth digit ratio and sensation seeking. Pers. Individ. Diff. 41, 1253-1262. doi: $10.1016 /$ j.paid.2006.05.002

Fischbacher, U. (2007). z-Tree: Zurich toolbox for ready-made economic experiments. Exp. Econ. 10, 171-178. doi: 10.1007/s10683-006-9159-4

Garbarino, E., Slonim, R., and Sydnor, J. (2011). Digit ratios (2D:4D) as predictors of risky decision making for both sexes. J. Risk Uncertain. 42, 1-26. doi: 10.1007/s11166-010-9109-6

Graham, J. R., Harvey, C. R., and Huang, H. (2009). Investor competence, trading frequency, and home bias. Manag. Sci. 55, 1094-1106. doi: $10.1287 / \mathrm{mnsc} .1090 .1009$

Green, C., Jegadeesh, N., and Tang, Y. (2009). Gender and job performance: evidence from wall street. Financial Anal. J. 65, 65-78. doi: 10.2469/faj.v65.n6.1

Greiner, B. (2004). The Online Recruitment System Orsee 2.0-a Guide for the Organization of Experiments in Economics. University of Cologne, Working paper series in economics, Vol. 10, 63-104.

Grinblatt, M., and Keloharju, M. (2009). Sensation seeking, overconfidence, and trading activity. J. Finance 64, 549-578. doi: 10.1111/j.1540-6261.2009.01443.x

Harrison, G. W., and Rutström, E. E. (2008). "Risk aversion in the laboratory," in Risk Aversion in Experiments, eds J. C. Cox and G. W. Harrison (Bingley: Emerald Group Publishing Limited), 41-196.

Hartgens, F., and Kuipers, H. (2004). Effects of androgenic-anabolic steroids in athletes. Sports Med. 34, 513-554. doi: 10.2165/00007256-20043408 0-00003

Hey, J. D. (2001). Does repetition improve consistency? Exp. Econ. 4, 5-54. doi: 10.1023/A:1011486405114

Hey, J. D., and Orme, C. (1994). Investigating generalizations of expected utility theory using experimental data. Econometrica 62, 1291-1326. doi: $10.2307 / 2951750$ 
Hollier, L. P., Keelan, J. A., Jamnadass, E. S. L., Maybery, M. T., Hickey, M., and Whitehouse, A. J. O. (2015). Adult digit ratio (2D:4D) is not related to umbilical cord androgen or estrogen concentrations, their ratios or net bioactivity. Early Hum. Dev. 91, 111-117. doi: 10.1016/j.earlhumdev.2014. 12.011

Hu, Y., Wang, D., Pang, K., Xu, G., and Guo, J. (2015). The effect of emotion and time pressure on risk decision-making. J. Risk Res. 18, 637-650. doi: $10.1080 / 13669877.2014 .910688$

Huber, O., and Kunz, U. (2007). Time pressure in risky decision-making: effect on risk defusing. Psychol. Sci. 49:415.

Jäkel, A., and Moynihan, T. (2016). Women in Financial Service 2016. London: Oliver Wyman Group.

Kaiser Family Foundation (2015). Employer Health Benefits [Online]. Kaiser Family Foundation and Health Research \& Educational Trust. Available online at: http://files.kff.org/attachment/report-2015-employer-health-benefitssurvey (Accessed Oct 18, 2017).

Kandasamy, N., Hardy, B., Page, L., Schaffner, M., Graggaber, J., Powlson, A. S., et al. (2014). Cortisol shifts financial risk preferences. Proc. Natl. Acad. Sci. U.S.A. 111, 3608-3613. doi: 10.1073/pnas.1317 908111

Kempel, P., Gohlke, B., Klempau, J., Zinsberger, P., Reuter, M., and Hennig, J. (2005). Second-to-fourth digit length, testosterone and spatial ability. Intelligence 33, 215-230. doi: 10.1016/j.intell.2004. 11.004

Kocher, M. G., and Sutter, M. (2006). Time is money-Time pressure, incentives, and the quality of decision-making. J. Econ. Behav. Organ. 61, 375-392. doi: 10.1016/j.jebo.2004.11.013

Kocher, M. G., Pahlke, J., and Trautmann, S. T. (2013). Tempus fugit: time pressure in risky decisions. Manag. Sci. 59, 2380-2391. doi: 10.1287/mnsc.2013. 1711

Korzec, R. (2000). The glass ceiling in law firms: a form of sex-based discrimination the glass ceiling law firms: a form of sex-based discrimination. J. Employ. Discrimination Law 251, 251-263.

Lattimore, P. K., Baker, J. R., and Witte, A. D. (1992). The influence of probability on risky choice: a parametric examination. J. Econ. Behav. Organ. 17, 377-400. doi: 10.1016/S0167-2681(95)90015-2

Lefevre, C. E., Wilson, V. A., Morton, F. B., Brosnan, S. F., Paukner, A., and Bates, T. C. (2014). Facial width-to-height ratio relates to alpha status and assertive personality in capuchin monkeys. PLoS ONE 9:e93369. doi: 10.1371/journal.pone.0093369

Lietz, N. G. (2012). In the Hot Finance Jobs, Women Are Still Shut Out. Cambridge, MA: Harvard Business School Publishing Corporation.

Lutchmaya, S., Baron-Cohen, S., Raggatt, P., Knickmeyer, R., and Manning, J. T. (2004). 2nd to 4th digit ratios, fetal testosterone and estradiol. Early Hum. Dev. 77, 23-28. doi: 10.1016/j.earlhumdev.2003.12.002

Manning, J. T. (2002). Digit Ratio: A Pointer to Fertility, Behavior, and Health. New Brunswick, NJ: Rutgers University Press.

Manning, J. T., and Taylor, R. P. (2001). Second to fourth digit ratio and male ability in sport: implications for sexual selection in humans. Evol. Hum. Behav. 22, 61-69. doi: 10.1016/S1090-5138(00)00063-5

Manning, J. T., Churchill, A. J., and Peters, M. (2007). The effects of sex, ethnicity, and sexual orientation on self-measured digit ratio (2D:4D). Arch. Sex. Behav. 36, 223-233. doi: 10.1007/s10508-007-9171-6

Manning, J. T., Scutt, D., Wilson, J., and Lewis-Jones, D. I. (1998). The ratio of 2nd to 4th digit length: a predictor of sperm numbers and concentrations of testosterone, luteinizing hormone and oestrogen. Hum. Reprod. 13, 3000-3004. doi: 10.1093/humrep/13.11.3000

Mazur, A., and Booth, A. (1998). Testosterone and dominance in men. Behav. Brain Sci. 21, 353-363. doi: 10.1017/S0140525X98001228

McIntyre, M. (2006). The use of digit ratios as markers for perinatal androgen action. Reprod. Biol. Endocrinol. 4:10. doi: 10.1186/1477-7827-4-10

Moffatt, P. G. (2005). Stochastic choice and the allocation of cognitive effort. Exp. Econ. 8, 369-388. doi: 10.1007/s10683-005-5375-6

Moore, C., and Tenbrunsel, A. E. (2014). "Just think about it"? Cognitive complexity and moral choice. Organ. Behav. Hum. Decis. Process. 123, 138-149. doi: 10.1016/j.obhdp.2013.10.006

Neyse, L., and Brañas-Garza, P. (2014). Digit Ratio Measurement Guide. Kiel: Kiel Institute for the World Economy (IfW).
Neyse, L., Bosworth, S., Ring, P., and Schmidt, U. (2016). Overconfidence, incentives and digit ratio. Sci. Rep. 6:23294. doi: 10.1038/srep23294

Niederle, M., and Vesterlund, L. (2007). Do women shy away from competition? do men compete too much?. Q. J. Econ. 122, 1067-1101. doi: $10.1162 /$ qjec.122.3.1067

Nursimulu, A., and Bossaerts, P. (2014). Excessive volatility is also a feature of individual level forecasts. J. Behav. Finance 15, 16-29. doi: 10.1080/15427560.2014.877016

Oberlechner, T., and Nimgade, A. (2005). Work stress and performance among financial traders. Stress Health 21, 285-293. doi: 10.1002/smi.1063

Powell, M., and Ansic, D. (1997). Gender differences in risk behaviour in financial decision-making: an experimental analysis. J. Econ. Psychol. 18, 605-628. doi: 10.1016/S0167-4870(97)00026-3

Rand, D. G. (2016). Cooperation, fast and slow: meta-analytic evidence for a theory of social heuristics and self-interested deliberation. Psychol. Sci. 27, 1192-1206. doi: 10.1177/0956797616654455

Rand, D. G., Greene, J. D., and Nowak, M. A. (2012). Spontaneous giving and calculated greed. Nature 489, 427-430. doi: 10.1038/nature11467

Rand, D. G., Peysakhovich, A., Kraft-Todd, G. T., Newman, G. E., Wurzbacher, O., Nowak, M. A., et al. (2014). Social heuristics shape intuitive cooperation. Nat. Commun. 5:677. doi: 10.1038/ncomms4677

Roberti, J. W. (2004). A review of behavioral and biological correlates of sensation seeking. J. Res. Pers. 38, 256-279. doi: 10.1016/S0092-6566(03) 00067-9

Roney, J. R., Mahler, S. V., and Maestripieri, D. (2003). Behavioral and hormonal responses of men to brief interactions with women. Evol. Hum. Behav. 24, 365-375. doi: 10.1016/S1090-5138(03)00053-9

Sapienza, P., Zingales, L., and Maestripieri, D. (2009). Gender differences in financial risk aversion and career choices are affected by testosterone. Proc. Natl. Acad. Sci. U.S.A. 106, 15268-15273. doi: 10.1073/pnas.0907352106

Saqib, N. U., and Chan, E. Y. (2015). Time pressure reverses risk preferences. Organ. Behav. Hum. Decision Process. 130, 58-68. doi: 10.1016/j.obhdp.2015.06.004

Schipper, B. C. (2014). Sex Hormones and Choice under Risk. University of California, Davis, Department of Economics Working Papers 147.

Sethi, B., Miller, E., and Philpott, R. (2013). Mending the Gender Gap: Advancing Tomorrow's Women Leaders in Fiancial Services. PricewaterhouseCoopers, Available online at: www.pwc.com

Stanton, S. J., Liening, S. H., and Schultheiss, O. C. (2011). Testosterone is positively associated with risk taking in the Iowa gambling task. Hormon. Behav. 59, 252-256. doi: 10.1016/j.yhbeh.2010. 12.003

Stigler, G. J., and Becker, G. S. (1977). De gustibus non est disputandum. Am. Econ. Rev. 67, 76-90.

Swerdloff, R. S., Wang, C., and Sinha Hikim, A. P. (2002). "The hypothalamic pituitary-gonadal axis in men," in Hormones, Brain and Behavior, eds D. W. Pfaff, A. P. Arnold, A. M. Etgen, S. E. Fahrbach, and R. T. Rubin (Amsterdam; London: Academic Press), 1-37.

Tester, N., and Campbell, A. (2007). Sporting achievement: what is the contribution of digit ratio? J. Pers. 75, 663-678. doi: 10.1111/j.1467-6494.2007. 00452.x

Truss, L. (2016). "RE: Women in the legal industry - GOV.UK," in Type to Spark21 Conference (London).

Valentine, K. A., Li, N. P., Penke, L., and Perrett, D. I. (2014). Judging a man by the width of his face: the role of facial ratios and dominance in mate choice at speed-dating events. Psychol. Sci. 25, 806-811. doi: 10.1177/0956797613 511823

Verdonck, A., Gaethofs, M., Carels, C., and de Zegher, F. (1999). Effect of low-dose testosterone treatment on craniofacial growth in boys with delayed puberty. Eur. J. Orthodontics 21, 137-143. doi: 10.1093/ejo/21.2.137

Wakker, P. P. (2010). Prospect Theory: For Risk and Ambiguity. Cambridge, UK: Cambridge University Press.

Weston, E. M., Friday, A. E., and Liö, P. (2007). Biometric evidence that sexual selection has shaped the hominin face. PLOS ONE 2:e710. doi: 10.1371/journal.pone.0000710

Wilcox, N. T. (2011). 'Stochastically more risk averse:'a contextual theory of stochastic discrete choice under risk. J. Econom. 162, 89-104. doi: 10.1016/j.jeconom.2009.10.012 
Williams, J. C., and Richardson, V. T. (2010). New Millennium, Same Glass Ceiling? The Impact of Law Firm Compensation Systems on Women, Chicago, II: The Project for Attorney Retention .

Williams, J. H., Greenhalgh, K. D., and Manning, J. T. (2003). Second to fourth finger ratio and possible precursors of developmental psychopathology in preschool children. Early Hum. Dev. 72, 57-65. doi: 10.1016/S0378-3782(03)00012-4

Young, D. L., Goodie, A. S., Hall, D. B., and Wu, E. (2012). Decision making under time pressure, modeled in a prospect theory framework. Organ. Behav. Hum. Decision Process. 118, 179-188. doi: 10.1016/j.obhdp.2012.03.005
Conflict of Interest Statement: The authors declare that the research was conducted in the absence of any commercial or financial relationships that could be construed as a potential conflict of interest.

Copyright $\odot 2017$ Xie, Page and Hardy. This is an open-access article distributed under the terms of the Creative Commons Attribution License (CC BY). The use, distribution or reproduction in other forums is permitted, provided the original author(s) or licensor are credited and that the original publication in this journal is cited, in accordance with accepted academic practice. No use, distribution or reproduction is permitted which does not comply with these terms. 